\title{
A Research about Mathematical Visualization Perceptions of Mathematics Teacher Candidates in Terms of Some Variables
}

\author{
Aziz ILHAN *1 (D) Tayfun TUTAK ${ }^{2}$ (D) \\ ${ }^{1}$ İnönü University, Faculty of Education, Malatya, Turkey, aziz.ilhan@inonu.edu.tr \\ ${ }^{2}$ Furat University, Faculty of Education, Elazı̆̆ Turkey, tayfuntutak@firat.edu.tr \\ * Corresponding Author: aziz.ilhan@inonu.edu.tr
}

Article Info

Received: 4 November 2020

Accepted: 14 December 2020

Keywords: Mathematical visualization perception, mathematics teacher candidates, mathematics education

DOI: $10.18009 /$ jcer.821211

Publication Language: English

\begin{abstract}
This study was conducted to examine mathematical visualization perceptions of mathematics teacher candidates in terms of gender, grade level, and parental educational status. Survey model was used. The population of the research consisted of mathematics teacher candidates who studied at the faculty of education of a university in the Southeastern Anatolia part of Turkey. The sample of the study consisted of 231 mathematics teacher candidates (159 Female, 72 Male) chosen by simple random sampling method from this population. In the study, Mathematical Visualization Perception Scale was used for getting data. The data were analyzed using SPSS. The descriptive analysis, study variable; average, percentage, and standard deviation were used. In addition, unpaired t-test for analyzing variation about gender variable, ANOVA, and LSD tests were preferred for analyzing variation about grade level and parental education status. As a result of the study findings, it was determined that the level of mathematical visualization perceptions of mathematics teacher candidates was no significant difference in terms of gender, but it was a significant difference in terms of grade level. Furthermore, math visualization perception level significantly differed according to parental education status.
\end{abstract}

To cite this article: İlhan, A., \& Tutak, T. (2021). A research about mathematical visualization perceptions of mathematics teacher candidates in terms of some variables. Journal of Computer and Education Research, 9 (18), 497-512. DOI: 10.18009/jcer.821211

\section{Introduction}

Visuals are in every part of our life, affect our lifestyle, and their importance of solving daily problems in daily life is getting increasingly higher every day. This paves the way for the concept of visual perception in individuals, and as a result of using and applying this concept, the visualization perception concept emerges. Although perception occurs with the interaction of all senses, the visual perception has an important place in perception. In visual perception, the individual recognizes and distinguishes visual stimuli and interprets them by combining them with previous experiences (Koç, 2002). Lappan (1999) defines visualization as cognitive comprehension of visual information. According to Arcavi (2003), visualization is a product, ability, and process of creation. In other words, it is a kind of 
suggesting the ideas that were unknown before and improving the understandings. Visual perception refers to information about the size, shape, and color of an object, and visualization includes the ability to mentally rotate and change two- and three-dimensional objects (Kurt, 2002).

With visualization, the concept of spatial thinking has emerged, and the concept of spatial visualization, which is the combination of these two concepts, has been included in the literature. Spatial visualization is defined as one of the most important subdivisions of spatial ability (Sezen-Yüksel \& Bülbül, 2014). Olkun and Altun (2003) define spatial ability as the ability to envision the new situations that will be occurred as a result of the movement of two-dimensional and three-dimensional objects and the parts them. Göktepe (2013) defines the concept of spatial visualization as the unfolding of a visually given object, the ability to rotate, twist or invert in the mind. The geometry learning area is seen as the learning area in which the concept of spatial visualization for mathematics is directly related and influenced. It is necessary to have spatial visualization skills to interpret geometric shapes, understand the relationships between shapes and visualize at the end of various transformations (Kösa, 2011). The individuals mostly believe that learning how to structure geometric figures and graphics, is enough for learning the visualization in math (Duval, 1998). Based on geometry, there are factors of visualization and drawing of geometric concepts and shapes, and generalization of them (Köse, 2008). A visual stimulus at the heart of this discipline supplies lots of information for organisms about the environment. Threedimensional visual-spatial figurations are based on visual clues. The world is sensed as three-dimensional, because the visual-spatial codes are three-dimensional (Kurt, 2002). These visualization and perception processes in geometry have brought geometric thinking along with it. Thus, together with geometry, the concept of geometric thinking was formed, and scientists researched this process. Duval (1998) reviews geometric thinking as three cognitive processes: visualization, formation, and reasoning. Visualization in this thinking process is the visual representation of the geometric expression or the intuitive or experimental exploration of a complex geometric situation.

Another concept that includes the concept of geometric thinking and is considered directly related to this concept is mathematical visualization. Mathematical visualization is the process of shaping images in the mind, with paper and pencil or with the help of technological tools, and using images effectively to explore and understand mathematics. 
(Zimmermann \& Cunningham, 1991). Mathematical visualization is exactly the ability of students to present a concept or problem, to use a diagram to support problem-solving to achieve understanding, to draw the appropriate diagram with pencil and paper, or in some cases using a computer (Uysal-Koğ \& Başer, 2012). Drawing a simple shape to express a mathematical problem, interpreting them comprehendingly, and using them as a support to solve problems are basic visualization skills (Zimmermann \& Cunningham, 1991). The fact that the individuals need a graphical approach to solve a problem, interpret the graph they draw to guide the algebraic approach and their intuitive thoughts play a role in leading them to the correct solution are the main parts of mathematical visualization that require highlevel skills. Appealing to more than one sense of the learner, which is a necessity of a modern learning environment, has highlighted the necessity of supporting the algebraic approach in mathematics with different approaches and the visualization approach (Uysal-Koğ \& Başer, 2012).

Visualization helps the individual with both configuring and isolating the concepts in math. As a matter of fact, according to Strong and Smith (2001), each individual has unique visualization skills. Moreover, it can improve the students' abilities to convert abstract concepts or systems into concrete or semiabstract environment or vice versa (Konyalığlu, 2003). Guzman (2002) stated four kinds of visualizations in terms of the similitude degree of concrete figuration and mathematical situation as follows:

1. Isomorphic visualization: Explaining the concrete concept that is isomorphs with the abstract concept that is perceived by the former senses in explaining the abstract concepts in math.

2. Homomorphic visualization: Using the homomorphic objects in the visualization

3. Analogical visualization: placing the studied object, which is already discovered to another object, the features and behaviors of which are known better.

4. Diagrammatic visualization: It presents schematically the common features and relations of objects in our minds and supports the thinking process.

\section{Literature Review}

The examination of the studies in the literature on the concept of visualization shows that studies on the concept of spatial visualization in mathematics education are also in the foreground (Topuz \& Birgin, 2020; Wakil, Khdir, Sabir, \& Nawzad, 2019). Sezen-Yüksel and Bülbül (2014) conducted an undergraduate level scale development study to measure spatial 
visualization ability. Olkun and Altun (2003) examined the relevance between students' computer experiences and spatial thinking and geometry success of primary education students. Delice, Aydın, and Kardeş (2009) evaluated the usage of visual items in math course books as if there were mathematics teacher candidates. Işık and Konyalıoğlu (2005) investigated the visualization approach in mathematics education and gave detailed information about this concept in the relevant study. Özdemir, Duru, and Akgün (2005) stated in their study that, in addition to traditional teaching techniques, using the visualization that made it possible for students to see some details better would improve the quality of identity teaching. Özer and Şan (2013) examined the effect of visualization on the learning level of identity. In this study, researchers examined the effects of visual materialaided teaching activity on teaching the subject of identities, by comparing the traditional teaching activity. Uysal-Koğ and Başer (2012) investigated the role of the visualization approaches in attitude and achievement towards mathematics and stated that the visualization approach has a positive effect on mathematics achievement and attitude. When these studies are examined, it is seen that the concept of visualization is important in mathematics education and should be used in teaching processes. It is also seen that the concept has been examined according to some variables. For example, Turgut and Yenilmez (2012) examined by mathematics teacher candidates' visualization skills in terms of gender in their study. Dündar, Yilmaz, and Terzi (2019) evaluated the spatial visualizations of mathematics teacher candidates in terms of gender and grade variables in their study. Based on these points, the mathematical visualization perceptions of mathematics teacher candidates, who will be the teachers of the future, were investigated in this study; It was evaluated in terms of gender, class, and parental education status variables. The fact that there is no study in which variables of the study about mathematics teacher candidates and statistical methods were included and the mathematical visualization perception was investigated after the literature review was conducted reinforces the original side of the study.

Aim of the Research and Sub-Problems

The aim of this study is to examine by mathematics teacher candidates' perceptions of mathematical visualization in terms of some variables. In line with this general purpose, the following sub-problems were sought:

Mathematical visualization perceptions of mathematics teacher candidates; 
1. How are the descriptive statistics?

2. Does it differ significantly in terms of gender variable?

3. Does it differ significantly in terms of the class variable?

4. Does it differ significantly in terms of the parental education status variable?

\section{Method}

\section{Research Design}

This study was conducted to examine whether the mathematical visualization perceptions of mathematics teacher candidates differ in terms of gender, grade level, and parental educational status. Therefore, the relational survey method was used. The relational survey method is expressed as a research model aimed at determining the presence or degree of change between two and more variables (Karasar, 2002).

\section{Research Participants}

The research participants consisted of mathematics teacher candidates who studied at the faculty of education of a midsize university in the Southeastern Anatolia part of Turkey. The sample of the study consisted of 231 mathematics teacher candidates (159 Female, 72 Male) chosen by simple random sampling method from this population. A simple random sampling method is a sampling type in which all units in the population have the chance to be selected equally and independently (Karasar, 2002).

\section{Data Collection Tools}

The Mathematics Visualization Perception Scale was developed by İlhan \& Tutak (2021). The scale consists of 42 5-Likert type items. The scale has 6 factors and these factors and Cronbach Alpha values are as follows: Additional Drawing (0.971), Spatial Thinking (0.977), Concept of Direction (0.976), Relationship with Daily Life (0.976), Transition from Algebra to Geometry (0.984) and Transition from Geometry to Algebra (0.987). Also, the Cronbach Alpha value of the scale was 0.938 and it was found to be 0.868 for this study (İlhan \& Tutak, 2021). The sample items related to the Mathematics Visualization Perception Scale are as follows: "If there is more than one additional drawing in a question, I believe that I can solve that question", "I can find the location of the vehicle I transport or park outside", "I can use what I learned in geometry in problem situations I encounter in my daily life", "Verbal I do not have difficulty solving geometry questions given as" I like algebraic operations in solving geometry problems. 


\section{Data Analysis}

The Mathematics Visualization Perception Scale was scored between 1 "Never" and 5 "Always". Levene test was conducted to determine whether the variances were homogeneously distributed in the study. Since Levene test result is $p>0,05$ for the scale $(Z=$ $0,483, p=0,81$ ) applications, it was determined that the variances are homogeneously distributed (Büyüköztürk, 2016). Also, the skewness and kurtosis values were analyzed and it was determined that these values were between -2 and +2 , and the z-skewness and $z$ kurtosis values were between -1.96 and +1.96 . However, it was observed that the mode, median, and arithmetic mean were also close to each other (Cameron, 2004). The ShapiroWilk test was conducted to determine whether the data were normally distributed. Findings related to this test are given in Table 1.

Table 1. Shapiro-Wilk test results of the scale

\begin{tabular}{lcccc}
\hline & Group & Statistics & df & $\mathrm{p}$ \\
\hline & Female & 0.95 & 158 & 0.26 \\
\cline { 2 - 5 } & Male & 0.96 & 71 & 0.36 \\
\cline { 2 - 5 } & 1. grade & 0.97 & 65 & 0.12 \\
\cline { 2 - 5 } Mathematics & 2. grade & 0.94 & 55 & 0.21 \\
\cline { 2 - 5 } Visualization & 3. grade & 0.95 & 53 & 0.34 \\
\cline { 2 - 5 } Perception & 4. grade & 0.93 & 54 & 0.16 \\
& Illiterate & 0.91 & 28 & 0.23 \\
\cline { 2 - 5 } & Primary School & 0.97 & 99 & 0.14 \\
\cline { 2 - 5 } & Secondary School & 0.92 & 38 & 0.18 \\
\cline { 2 - 5 } & High School & 0.94 & 41 & 0.19 \\
\cline { 2 - 5 } & University & 0.95 & 20 &
\end{tabular}

Büyüköztürk (2016) stated that if the group size is less than 50, the Shapiro-Wilks test should be used to examine the conformity of the scores to normality. For this reason, the Shapiro-Wilk test was preferred. As a result, it was determined that the scale applications were $(p>0.05)$ for each data set and showed normal distribution. With the help of research data, whether or not the visualization perception levels of mathematics teacher candidates differ in terms of gender variables, was examined by an independent sample t-test, and whether there is a difference in terms of grade level and parental education status was 
examined by one-way analysis of variance (ANOVA). The LSD test was used to determine that this difference is between in which classes or parental education status.

\section{Findings}

In this part of the study, the mathematical visualization perception levels of the mathematics teacher candidates were examined in terms of variables of gender, class, and parental education status. First, descriptive statistics were investigated in the study, then it was examined whether the difference regarding the variables was significant or not. Descriptive Statistics of Mathematics Teacher Candidates' Math Visualization Perception Levels

The descriptive statistics of mathematics teacher candidates' math visualization perception levels are shown in Table 2.

Table 2. The descriptive statistics of mathematics teacher candidates' math visualization perception levels

\begin{tabular}{lcccc}
\hline & $\mathrm{N}$ & $\mathrm{M}$ & $\%$ & $\mathrm{SD}$ \\
\hline Mathematical Visualization Perception & 231 & 3.40 & 68.46 & 0.66 \\
\hline
\end{tabular}

When the perception of mathematical visualization in Table 2 is compared, it is determined that the mean of 3.40 and percentage of $\% 68.46$.

Findings Regarding the Mathematics Visualization Perception Levels of Mathematics Teacher Candidates According to Gender Variable

The descriptive statistics of gender variables are shown in Table 3.

Table 3. The descriptive statistics of gender variables

\begin{tabular}{llllll}
\hline & Gender & $\mathrm{N}$ & $\mathrm{M}$ & $\%$ & $\mathrm{SD}$ \\
\hline \multirow{2}{*}{ Mathematical Visualization Perception } & Female & 159 & 3.36 & 67.22 & 0.63 \\
& Male & 72 & 3.44 & 69.70 & 0.77 \\
\hline
\end{tabular}

When the perception of mathematical visualization in Table 3 is compared according to gender variable, it is determined that the percentages of male are higher than females. After analyzing the descriptive statistics about the gender variable, independent sample t-test statistics of the gender variable were conducted (Table 4).

Table 4. t-test results of mathematical visualization perception scores according to gender variables 
Ilhan $\mathcal{E}$ Tutak

\begin{tabular}{lcccccc}
\hline Gender & $\mathrm{N}$ & $\mathrm{M}$ & $\mathrm{SD}$ & $\mathrm{df}$ & $\mathrm{t}$ & $\mathrm{p}$ \\
\hline Female & 159 & 3.36 & 0.63 & \multirow{2}{*}{0.49} & -0.75 & 0.46 \\
Male & 72 & 3.44 & 0.77 & & & \\
\hline
\end{tabular}

According to Table 4, mathematical visualization perception mean scores of female mathematics teacher candidates are lower than the mean scores of males. However, the difference between these mean scores was not statistically significant [ $t(229)=-0.75 ; p>0.05]$. Findings Regarding the Mathematics Visualization Perception Levels of Mathematics Teacher Candidates According to Grade Level Variable

Descriptive statistics related to grade-level were analyzed and the results were given in Table 5 .

Table 5. The descriptive statistics of grad-level

\begin{tabular}{|c|c|c|c|c|c|c|c|}
\hline & & & Grade & $\mathrm{N}$ & $\mathrm{M}$ & $\%$ & $\mathrm{SD}$ \\
\hline \multirow{4}{*}{ 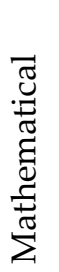 } & \multirow{4}{*}{ 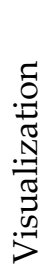 } & \multirow{4}{*}{ 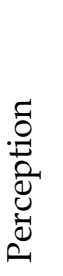 } & 1. grade & 66 & 3.30 & 66.08 & 0.74 \\
\hline & & & 2. grade & 56 & 3.35 & 66.98 & 0.60 \\
\hline & & & 3. grade & 54 & 3.57 & 71.48 & 0.39 \\
\hline & & & 4. grade & 55 & 3.42 & 68.34 & 0.83 \\
\hline & & & & 231 & 3.41 & 68.12 & 0.67 \\
\hline
\end{tabular}

The percentage values of the variables in Table 5 shows that mathematics teacher candidates have a mathematical visualization perception with a ratio of approximately $68.12 \%$. When mathematics visualization perceptions of mathematics teacher candidates are evaluated, it is seen that the perception of visualization from the first grade to the third grade increased while the fourth grade decreased compared to the third grade. The difference between the mathematical visualization perception scores of mathematics teacher candidates was investigated by ANOVA and LSD tests. The results are shown in Table 6 .

Table 6. ANOVA and LSD results on mathematical visualization perception scores by grade level 
Ilhan $\mathcal{E}$ Tutak

\begin{tabular}{lcccccc}
\hline Grade & $\mathrm{N}$ & $M$ & $S D$ & $F$ & $p$ & LSD \\
\hline 1. Grade & 66 & 3.30 & 0.74 & & & \\
2. Grade & 56 & 3.35 & 0.60 & & & $1<3(\mathrm{p}=0.03)$ \\
3. Grade & 54 & 3.57 & 0.39 & 2.61 & 0.04 & $2<3(\mathrm{p}=0.01)$ \\
4. Grade & 55 & 3.42 & 0.83 & & & \\
\hline Total & 231 & 3.41 & 0.67 & & & \\
\hline
\end{tabular}

According to Table 6, the mathematical visualization perception average of the thirdgrade mathematics teacher candidates is higher than the other grades, and the mathematical visualization perception average of the first-grade mathematics teacher candidates is the lowest. As a result of the ANOVA test, the difference between the mean scores of mathematical visualization perception was found to be statistically significant $\left(F_{2,229}=2.61 ; p\right.$ $<0.05)$. The LSD test was used to investigate the difference between the groups and the difference between the mathematical visualization perception scores of the mathematics teacher candidates at the third grade and the mathematical visualization perception scores of the first and second-grade mathematics teacher candidates were found to be significantly different in favor of the third-grade students.

Findings Regarding the Mathematics Visualization Perception Levels of Mathematics Teacher Candidates According to Parental Education Status Variable

Descriptive statistics about parental education status are presented in Table 7.

Table 7. Descriptive statistics about parental education status

\begin{tabular}{|c|c|c|c|c|c|c|c|}
\hline & & & Education Status & $\mathrm{N}$ & $M$ & $S D$ & $\%$ \\
\hline \multirow{5}{*}{ 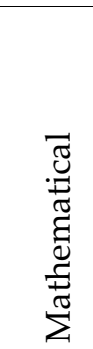 } & \multirow{5}{*}{ 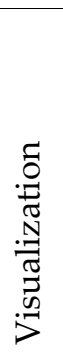 } & \multirow{5}{*}{ 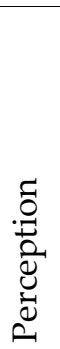 } & Illiterate & 29 & 3.22 & 0.71 & 64.30 \\
\hline & & & Primary School & 100 & 3.28 & 0.77 & 65.64 \\
\hline & & & Secondary School & 39 & 3.43 & 0.41 & 68.66 \\
\hline & & & High School & 42 & 3.58 & 0.60 & 71.64 \\
\hline & & & University & 21 & 3.59 & 0.53 & 71.70 \\
\hline Total & & & & 231 & 3.38 & 0.67 & 67.62 \\
\hline
\end{tabular}

When the mathematical visualization perceptions of the mathematics teacher candidates in Table 6 are analyzed, it is seen that the perception of visualization increases as 
the education level of parents increases. After the difference between the mathematical visualization perception scores of mathematics teacher candidates was investigated by grade variable, ANOVA and LSD tests were used to determine whether there was a significant difference according to parental education status. The results are shown in Table 8 .

Table 8. ANOVA and LSD results related to mathematical visualization perception scores according to the parental educational status variable

\begin{tabular}{lllllll}
\hline Parental Educational Status & $\mathrm{N}$ & $\mathrm{M}$ & $\mathrm{SD}$ & $F$ & $p$ & LSD \\
\hline (A) Illiterate & 29 & 3.22 & 0.71 & & & \\
(B) Primary School & 100 & 3.28 & 0.77 & & & $\mathrm{~A}<\mathrm{D}(p=0.02)$ \\
(C) Secondary School & 39 & 3.43 & 0.41 & 2.53 & 0.04 & $\mathrm{~B}<\mathrm{D}(p=0.02)$ \\
(D) High School & 42 & 3.58 & 0.60 & & & \\
(E) University & 21 & 3.59 & 0.53 & & & \\
\hline
\end{tabular}

According to Table 8, the mathematical visualization perception scores of the mathematics teacher candidates whose parents are educated at the university level are higher than the other groups and the mathematics teacher candidates in the illiterate group have the lowest mean mathematical visualization perception scores. The mathematical visualization perception mean scores of mathematics teacher candidates were statistically significant $(F 2,229=2.53 ; p<0.05)$. The differences between these groups were investigated by LSD test, mathematical visualization perception scores of mathematics teacher candidates whose parental education status is high school and non-illiterate and mathematical visualization perceptions of mathematics teacher candidates whose parental education status is primary school level were found to be significantly different in favor of those whose parental education status is high school.

\section{Discussion and Conclusion}

In this study, the mathematical visualization perception levels of the mathematics teacher candidates who will be the instructors of the future were investigated in terms of gender, class, and parental education status. The mathematical visualization perception scores of the male mathematics teacher candidates included in the study were higher than the female mathematics teacher candidates while there was no significant difference between 
the mathematical visualization perception scores in terms of gender variable. In other words, mathematical visualization perception scores of female and male mathematics teacher candidates are similar. A brief literature review shows that it is possible to find similar or overlapping studies similar to the results of this study (Dokumacı-Sütçü, 2021; Orhun, 2007). Çelik (2018) stated that students' mathematics visualization perception did not change in terms of gender variables. Ünlü (2014) stated in his study with eighth-grade students that the spatial visualization skills of the secondary school students were low and the geometry achievements were moderate. According to the results of the study conducted by Rafi, Samsudin, and Said (2008), it is emphasized that the spatial visualization ability is higher in male students than in female students. Dursun (2010) determined that the spatial visualization scores of boys were found to be significantly higher than girls'. Orhun (2007) found that there was a cognitive deficiency between formal arithmetic and visualization in his study on fractions with fourth-grade students. Although the researcher found no significant difference between female and male students in this study, he determined that the perception of visualization was low in general. Burin, Delgado, and Prieto (2000) stated that there is no significant difference in spatial visualization tasks according to gender in their study of solution strategies and gender variables in spatial visualization tasks. Orhun (2007) reported that male students were more successful than girls in visualization questions about fractions. In the study, it was also found that in general, there was no significant difference between female and male students in terms of their success in fractions. Kakmaci (2009) found that the spatial visualization skills of male students were higher than the female students in his study with sixth-grade students. In the study of Abay, Tertemiz, and Gökbulut (2018), the mean score of the mathematics teacher candidates obtained from the spatial visualization test did not show a significant difference according to their gender. Turgut and Yenilmez (2012) found that mathematics teacher candidates had low spatial visualization skills and did not differ according to gender variable.

When mathematics visualization perception scores of mathematics teacher candidates are evaluated in terms of grade variable, it is seen that mathematical visualization perception mean scores of the third-grade mathematics teacher candidates are higher than the other mathematics teacher candidates in the other grades and the mean scores of the mathematics teacher candidates in the first grade are the lowest. The difference between the mathematical visualization perception mean scores was seen as statistically significant. The mathematical 
visualization perception scores of the mathematics teacher candidates at the third-grade level and the mathematical visualization perception scores of the first and second-grade mathematics teacher candidates were found to be in favor of the third-grade students. In other words, the grade level of mathematics teacher candidates has had an impact on visualization perceptions. The reason for this may be that mathematics teacher candidates have taken the pedagogy or geometry lessons in undergraduate education. It is possible to come across a study determined that spatial abilities do not make a significant difference in terms of grade variable. Dokumacı-Sütçü (2018) did not find a significant difference between the mean scores of the mathematics teacher candidates on the spatial abilities.

In the study, the mathematical indicators of mathematics teacher candidates according to their parental education status were examined. As a result, it was seen that the mathematical visualization perception scores of the mathematics teacher candidates at the university level were higher than the other groups, and the mean scores of the illiterate teachers were the lowest. In other words, mathematical visualization perceptions of mathematics teacher candidates increased as parental education status increased. This difference was significant between the mathematical visualization perception to mean scores. In other words, the maternal and paternal education status of teacher candidates was effective in mathematical visualization perceptions. When a literature review is performed, it is possible to find similar or overlapping studies like the results of this study. Behavioral psychologists are also of the opinion that the source of difference in spatial ability is related to the family's educational status, child-rearing, learning opportunities, and social expectations (Sundberg, 1994).

As a result, the mathematical visualization perception means scores of male mathematics teachers who were included in the study were higher than female mathematics teacher candidates while there was no significant difference between the mathematical visualization perception scores. When mathematics visualization perception scores of mathematics teacher candidates are evaluated in terms of class variable, it is seen that mathematical visualization perception mean scores of the third-grade teachers are higher than the other teacher candidates in the other classes and the mean scores of the teacher candidates in the first grade are the lowest. The difference between the mathematical visualization perception mean scores was statistically significant for the class variable. It was seen that the mathematical visualization perception scores of the mathematics teacher 
candidates whose parental education status was at the university level, were higher than the other groups, and the mathematical visualization perception scores of the teachers who are not literate were the lowest. Also, this difference between the mathematical visualization perception mean scores was statistically significant. Within the scope of the findings of the study, the following suggestions were made to the researchers who want to work in this field in the future:

- Mathematics teacher candidates in the Southeastern Anatolia region were included in the study. Therefore, the perceptions of mathematical visualization of mathematics teacher candidates can be evaluated by choosing a sample group with a wider audience (in different departments or universities).

- Gender, grade, and parental education status variables were included in the study. Mathematical visualization perceptions of teacher candidates can be evaluated by considering different variables.

- The relationship between mathematical visualization perceptions and other cognitive or affective skills of mathematics teacher candidates can be examined by using statistics such as correlation, regression, or path analysis.

Acknowledgment

It has been confirmed by the researchers that the data used in this study are dated before 2020.

\section{Author Contribution Statement}

Aziz ILHAN: Conceptualization, methodology, measurement tool, data analysis, reviewwriting, and editing.

Tayfun TUTAK: Conceptualization, methodology, data collection, consultancy, and control preliminary draft writing and editing.

\section{References}

Abay, S., Tertemiz, N., \& Gökbulut, Y. (2018). Invastigation in several variables the spatial skills of teacher candidates. Necatibey Faculty of Education Electronic Journal of Science and Mathematics Education, 12(1), 45-62.

Arcavi, A. (2003). The role of visual representations in the learning of mathematics. Educational Studies in Mathematics, 52(1), 215-241.

Burin, D. I., Delgado, A. R., \& Prieto, G. (2000). Solution strategies and gender differences in spatial visualization tasks. Journal of Psicológica, 21(2), 275-286. 
Büyüköztürk, Ş. (2016). Data analysis manual (22nd Edition). Ankara: Pegem Academy.

Cameron, A. C. (2004). Kurtosis. In M. S. Lewis-Beck, M. Bryman, A., \& Liao, T. F. (Eds.), The Sage Encyclopedia of Social Science Research Methods. California: SAGE Publications, pp. 544-545.

Çelik, H. C. (2018). Investigating the visual mathematics literacy self-efficacy (VMLSE) perceptions of eighth grade students and their views on this issue. International Journal of Educational Methodology, 5(1), 165-176.

Delice, A., Aydın, E., \& Kardeş, D. (2009). The use of visual objects in mathematics textbooks from the perspective of teacher candidate. Istanbul Commerce University Journal of Science, 8(16), 75-92.

Dokumac1-Sütçü, N. (2018, November). Examining the environmental spatial abilities of prospective teachers. International Social Sciences and Education Conference (ISSEC 2018), 14-17 November 2018, Diyarbakır, Turkey.

Dokumac1-Sütçü, N. (2021). Investigation of the relationship between spatial habits of mind and visual literacy competences through structural equation model. Journal of Computer and Education Research, 9(17), 125-144. DOI: 10.18009/jcer.840318

Dursun, Ö. (2010). The relationships among preservice teachers'spatial visualization ability, geometry self-efficacy, and spatial anxiety. Master's Thesis, Middle East Tecnichal University, Institute of Educational Sciences, Ankara.

Duval, R. (1998). Geometry from a cognitive point of view. In C. Mammana and V. Villani (Eds.), Perspectives on the Teaching of Geometry for the 21st Century: An ICMI study, (pp.37-52). Dordrecht: Kluwer.

Dündar, M., Yılmaz, R., \& Terzi, Y. (2019). Investigating spatial ability of pre-service mathematics and primary school teachers. OMU Journal of Education Faculty, 38(1), 113130.

Göktepe, S. (2013). Investigation of the spatial abilities of elementary mathematics teacher candidates with solo model. Master's Thesis, Marmara University, Institute of Educational Sciences, İstanbul.

Guzman, M. (2002). The role of visualization in the teaching and learning of mathematical analysis. In Proceedings of International Conference on the Teaching of Mathematics (at the Undergraduate Level), Hersonissos, Greece. (ERIC Document Reproduction Service No.ED 472 047).

Işık, A., \& Konyalıoglu, A. C. (2005). Visualization approach in mathematics education. Journal of Kazım Karabekir Education Faculty, 11(1), 462-471.

İlhan, A., \& Tutak, T. (2021). A scale development study intended for mathematics teacher candidates: mathematical visualization perception scale. International Electronic Journal of Mathematics Education, 16(1), 1-11.

Kakmac1, Ö. (2009). Investigation of the sixth grade students' spatial visualization success in terms of some variables. Master's Thesis, Eskişehir Osmangazi University, Institute of Educational Sciences, Eskişehir.

Karasar, N. (2002). Scientific research method (11th edition). Ankara: Nobel Publication. 
Koç, E. (2002). Preparation of a sample model pertaining to the development of visual-perceptual skills and investigation of its effects on the development of visual perception in preschool children. Master's Thesis, Gazi University, Institute of Educational Sciences, Ankara.

Konyalığlu, A. C. (2003). Investigation of effectiveness of visualization approach on understanding of concepts in vector spaces at the university level. Doctoral Dissertation, Atatürk University Institute of Sciences, Erzurum.

Kösa, T. (2011). An investigation of secondary school students? Spatial skills. Doctoral Dissertation, Karadeniz Technihal University, Institute of Educational Sciences, Trabzon.

Köse, N. Y. (2008). Determining fifth grade primary school students? understanding of symmetry using dynamic geometry software cabri geometry: An action research. Doctoral Dissertation, Anadolu University, Institute of Educational Sciences, Eskişehir.

Kurt, M. (2002). Components of visuospatial abilities. Journal of Clinical Psychiatry, 5(1), 120125.

Lappan, G. (1999). Geometry: The forgotten strand. NCTM News Bulletin, 36(5), 3-17.

Olkun, S., \& Altun, A. (2003). The relationship between computer experience of elementary school students and spatial thinking and geometry achievements. The Turkish Online Journal of Educational Technology, 2(4), 86-91.

Orhun, N. (2007). A cognitive gap between formal arithmetic and visual representation in fractional operations. Inönü University Journal of the Faculty of Education, 8(14), 99-111.

Özdemir, M. E, Duru, A., \& Akgün, L. (2005). Two and three dimensional thinking: visualization of some identities with two and three dimensional geometric shapes. Kastamonu Education Journal, 13(2), 527-540.

Özer, M. N., \& Şan, İ. (2013). The effect of visualization on reaching the subject of identities. International Journal of Social Science, 6(1), 1275-1294.

Rafi, A., Samsudin, K. A., \& Said, C. S. (2008). Training in spatial visualization: the effects of training method and gender. Educational Technology \& Society, 11(3), 127-140.

Sezen-Yüksel, N., \& Bülbül, A. (2014). Test development study on the spatial visualization. Necatibey Faculty of Education Electronic Journal of Science and Mathematics Education, 8(2), 124-142.

Strong, S., \& Smith, R. (2001). Spatial visualization: Fundamentals and trends in engineering graphics. Journal of Industrial Technology, 18(1), 1-6.

Sundberg, S. E. (1994). Effect of spatial training on spatial ability and mathematical achievement as compared to traditional geometry instruction. Doctoral Theses, University of MissouriKansas City.

Topuz, F., \& Birgin, O. (2020). Students' views about geogebra-supported teaching material and learning environment developed for "circle and disc" subject at the 7th grade. Journal of Computer and Education Research, 8(15), 1-27.

Turgut, M., \& Yenilmez, K. (2012). Spatial visualization abilities of preservice mathematics teachers. Journal of Research in Education and Teaching, 1(2), 243-252. 
Uysal-Koğ, O., \& Başer, N. (2012). The role of visualization approach on students' attitudes towards and achievements in mathematics. Elementary Education Online, 11(4), 945-957.

Ünlü, M. (2014). Factors affecting geometry success: A structural equation modelling. Doctoral Dissertation, Necmettin Erbakan University, Institute of Educational Sciences, Konya.

Wakil, K., Khdir, S., Sabir, L., \& Nawzad, L. (2019). Student ability for learning computer programming languages in primary schools. International e-Journal of Educational Studies, 3(6), 109-115.

Zimmermann, W., \& Cunningham, S. (1991). Editor's introduction: What is mathematical visualization. In W. Zimmermann and S. Cunningham (Eds.). Visualization in Teaching and Learning Mathematics, (pp. 1-8). Mathematical Association. 